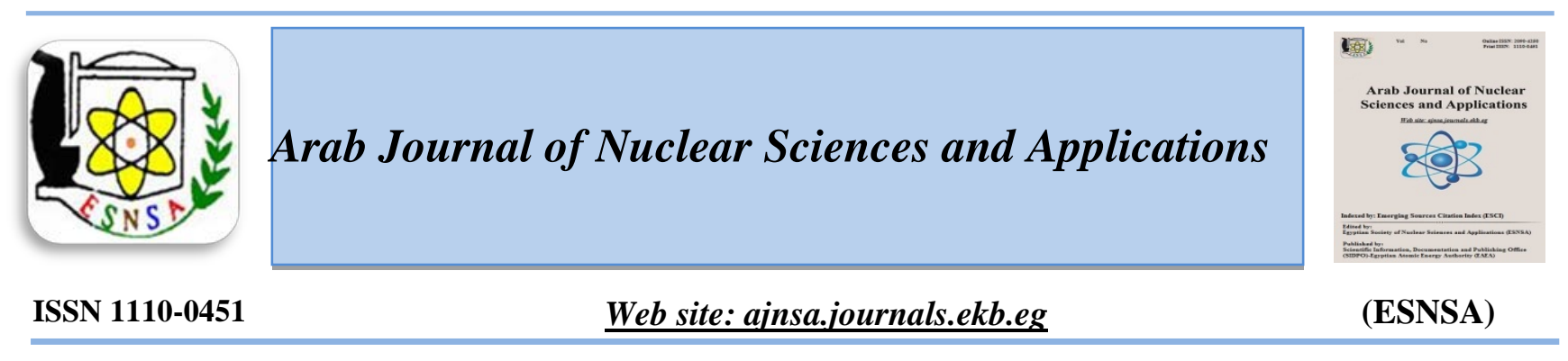

\title{
Oral N-Acetyl Cysteine Administration Improved Oxidative Status in Medical Radiation Workers
}

\author{
M.S. Abou El-Eneen ${ }^{(1)}$, M.I. Morsi ${ }^{(1)}$ and M. A. Soula ${ }^{(2)}$ \\ (1) Department of Radiation Sciences, Medical Research Institute, Alexandria University, Alexandria, Egypt \\ (2) Radiology Department, Qotour Central Hospital, El Gharbeya, Egypt
}

\begin{abstract}
Received $1^{\text {st }}$ Oct. 2019 Medical radiation workers (MRWs) are chronically exposed to low doses of ionizing radiation which has Accepted $5^{\text {th }}$ March 2020 been reported to cause deleterious health effects resulting from oxidative stress. N-acetyl cysteine (NAC) is the promise choice for treating disorders resulting from excessive production of reactive oxygen species (ROS). The aim of the present study was to investigate the role of NAC in protecting medical workers occupationally exposed to low doses of ionizing radiation (IR) via detecting some oxidative stress markers and comparing the results with controls. The studied participants were divided into healthy MRWs administered NAC effervescent $600 \mathrm{mg}$, as a radioprotector $(\mathrm{n}=50)$ and healthy nonradiation workers as control group $(n=50)$. Two blood samples were taken from MRWs; before and after taking of NAC and one blood sample from the control group to detect reduced erythrocyte glutathione (GSH), plasma malondialdehyde (MDA) and advanced oxidation protein products (AOPPs). Erythrocyte GSH levels were significantly decreased in MRWs group compared tothe control group and significantly increased after oral administration of NAC. Plasma levels of MDA and AOPPs in MRWs group were significantly increased than control group, while their levels were significantly reduced after taking NAC. These findings suggest using of NAC as a promising radioprotector for medical workers occupationally exposed to low dose of IR to reduce the resulted oxidative stress.
\end{abstract}

Key words: Radiation Workers, Chronic Exposure, Oxidative Stress, Radioprotector, N-Acetyl Cysteine (NAC)

\section{Introduction}

Ionizing radiation (IR) has a double edged sward. Although the use of $\mathrm{X}$-rays made a revolution in the diagnosis of many diseases and are applied in the treatment of cancer. However, persistent exposure to low radiation doses has been found to cause deleterious health effects [1, 2].

Healthcare radiation workers are exposed to low doses of IR from different sources, including diagnostic $\mathrm{x}$-rays and more medical devices [1] .The risk of cardiovascular diseases, cataract of the eyes, lung disease and variety of cancers has been reported as a result of chronic exposure to low dose of IR [3,4]. The estimation of cancer risk in female radiation workers were higher than male (391.2/100,000 and 264.4/100,000, respectively) [5].
The main cause of the harmful effect of IR is the formation of reactive oxygen species (ROS) through radiolysis of water molecules which subsequently oxidize macromolecules including DNA, proteins and lipids that leads to increase in the oxidative stress and genomic instability that leads to many pathological diseases [6].

Cellular oxidative stress depletes reduced glutathione (GSH), which is associated with many pathological disorders. It is a crucial protecting molecule in cells against damage of free radicals as it may act as a substrate or cofactor of antioxidant enzymes and as a perfect radical trapping [7].

Reactive oxygen species disrupt membrane structure and function via oxidative damage of polyunsaturated fatty acids found in the cell membranes and also produces potentially

Corresponding author: marwa.aboueleneen@alexu.edu.eg

DOI: $\underline{10.21608 / a j n s a .2020 .17667 .1279}$

(C) Scientific Information, Documentation and Publishing Office (SIDPO)-EAEA 
mutagenic and carcinogenic byproducts. Malondialdehyde (MDA) is one of the cytotoxic products of lipid peroxidation, which was increased in the hospital workers exposed to low doses of radiation $[6,8]$.

Reactive oxygen species are naturally formed inside the cells but in lower concentrations as they act as regulators of the cellular functions. However, the overwhelming accumulation of ROS induced by continuous exposure to IR disrupts the balance between pro-oxidant and antioxidant mechanisms which leads to oxidative cellular damage [6].

Cumulative production of ROS induces oxidative damage to proteins. ROS has high affinity to react with sulfur-containing amino acids and proteins containing metal ions causing reversible and irreversible damage. This damage is reflected by increased levels of advanced oxidation protein products (AOPPs) $[9,10]$.

Thus, there is a need for a radioprotector to suppress ROS production and conserve the prooxidant and antioxidant balance to reduce the hazards of chronic exposure to IR.

$\mathrm{N}$-acetyl cysteine (NAC) is a universal cheap drug and has been used since 1960 [11]. It has been used as a therapeutic option in many disorders including respiratory, renal and psychiatric diseases and also used in the treatment of male infertility and polycystic ovary syndromes. It has been used as antidote to acetaminophen overdose. [7, 12-15] It was approved by the Food and Drug Administration and used as a dietary antioxidant supplement. It is a small thiol molecule that protect healthy cells against radiation induced genotoxicity [16].

$\mathrm{N}$-acetyl cysteine is a promising choice for treating disorders resulting from excessive production of ROS as it has the ability to scavenge free oxygen radicals and eliminate ROS. It enhances the levels of reduced GSH and glutathione S-transferase activity [17]. It restitutes impaired targets in vital cellular components through hydrogen donation from -SH [16].

The present study was designated to investigate the role of $\mathrm{N}$-acetyl cysteine in protecting medical workers occupationally exposed to low doses of ionizing radiation via detecting some oxidative stress markers and comparing the results with controls.

\section{Materials And Methods}

This study was performed from December 2017 to August 2018 and it included 100 healthy workers that were divided into two groups according to exposure to radiation:

Group I: 50 healthy medical workers occupationally exposed to radiation were selected from diagnostic radiology departments from many hospitals and radiology centers. They received Nacetyl cysteine effervescent $600 \mathrm{mg}$ (SEDICO Pharmaceutical Co.) as a radioprotector, two times a day for two months. Group II: 50 healthy nonradiation workers as a control group (matched age and sex with group I) and they were chosen from the same hospitals but did not have any work related to IR exposure.

Two peripheral blood samples were assembled from group I, one sample was taken before intake of NAC and the other after two months. Only one sample was drawn from the workers of the second group. Each worker included in the study was asked to freely volunteer and an informed written consent was gathered from each one prior to inclusion in the study protocol. This study protocol was approved by the Ethical Guidelines of the Medical Research Institute, Alexandria University, Egypt.

\section{Inclusion criteria}

The selected workers should have no viral or bacterial infections, no malignant tumors, no severe chronic diseases, no serious tobacco dependence, and non-alcoholic habits.

\section{Blood sampling and biochemical analysis}

Each collected blood sample was divided into three tubes containing ethylenediaminetetraacetic acid (EDTA). Erythrocytes in the first tube was lysed to prepare GSH. The other two blood tubes were centrifuged at 3,000 rpm for $10 \mathrm{~min}$ at $4^{\circ} \mathrm{C}$ then the plasma was pipetted off and stored on ice until assaying or freezed at $-80^{\circ} \mathrm{C}$ to assess AOPPs and MDA.

Reduced GSH and MDA were measured by Colorimetric method kit (Bio-diagnostic, Giza, Egypt). AOPPs was detected by an Enzyme-linked Immunosorbent Assay (ELISA) (MyBiosource, Inc., USA). 


\section{Statistical analysis}

Data were analyzed using IBM SPSS software package version 20.0. The Kolmogorov-Smirnov test was utilized to verify the normality of distribution. Quantitative data were described using median, mean and standard deviation. Significance of the obtained results was judged at the 5\% level. Student t-test and Mann Whitney test were used to compare between two studied groups. Paired t-test and Wilcoxon signed ranks test were utilized for to compare between two periods ${ }^{(18,19)}$.

\section{Results}

\section{Study participants}

Table (1) showed information regarding age, sex, working hours per week, duration of exposure, and average annual effective dose of medical radiation workers (MRWs). The mean age of the control group was approximately the same as the MRWs group (41.6 \pm 5.7 and $41.9 \pm 4.8$ years, respectively). Most of the workers were male (86\%). Analysis of the data showed that all MRWs average annual effective doses were below the annual permissible limit of $20 \mathrm{mSv}$ prescribed by International

Commission on Radiological Protection (ICRP). Nutritional style was not included in our analysis as all the participants were non-vegetarian and none of the study included subjects had a particular dietary habit.
The medical radiation workers group were subdivided into three subgroups according to their working sectors; conventional radiology (CR), interventional radiology (InR) and computed tomography (CT) subgroups. Analysis of the data showed that about half of workers were employed in the CR sectors, while the minority of them were working in the InR sectors and approximately one third were in the CT sectors; 48, 16 and 36\%, respectively. The data displayed that the least average annual effective dose was found in the CR subgroup $(0.2 \pm 0.14 \mathrm{mSv})$ and it was significantly lower than both the InR and the CT subgroups. However, the highest average annual effective dose was in the InR subgroup and it was significantly higher than the CT subgroup. It was observed that the average annual effective dose for the CR and the CT subgroups was lower than 1 $\mathrm{mSv}$, Table 2 .

\section{Comparison between both groups}

The medical radiation workers group showed a significant decrease in GSH levels when compared to the control group with marked differences among the occupational setting subgroups $(\mathrm{P}<$ 0.001 ) and the least levels were found in InR subgroup. A significant difference was found between $\mathrm{CR}$ and InR subgroups $(0.03 \pm 0.02$ and $0.01 \pm 0.01 \mathrm{mmol} / \mathrm{L}$, respectively, $\mathrm{P}=0.037$ ), while no significant differences were found between CT versus CR and InR subgroups ( $\mathrm{P}>0.05)$, Table (3), Figure (1).

Table (1): Information of Medical radiation workers

\begin{tabular}{lcc}
\hline \multicolumn{1}{c}{ Parameters } & Min. - Max. & Mean \pm SD \\
\hline Age (year) & $31-54$ & $41.6 \pm 5.7$ \\
Hours/week (Hr) & $10-80$ & $46.6 \pm 19.1$ \\
Duration of Exposure (year) & $10-31$ & $20.3 \pm 5.4$ \\
Average annual effective dose (mSv/y) & $0.05-5.5$ & $1.00 \pm 1.36$ \\
\hline
\end{tabular}

Table (2): Classification of Medical radiation workers and their average annual effective doses.

\begin{tabular}{lcccc}
\hline \multicolumn{2}{c}{ Parameters } & \multicolumn{3}{c}{ Radiation exposed workers } \\
& & CR & CT & InR \\
\hline No. (\%) & & $24(48.0 \%)$ & $18(36.0 \%)$ & $8(16.0 \%)$ \\
Average annual & Min. - Max. & $0.05-0.47$ & $0.22-2.20$ & $2.74-5.5$ \\
effective dose & Mean \pm SD & $0.2 \pm 0.14$ & $0.87 \pm 0.67$ & $3.7 \pm 1.11$ \\
$(\mathrm{mSv} / \mathrm{y})$ & median & 0.15 & 0.61 & 3.4 \\
Probability & P1 & & $<0.001^{* *}$ & $<0.001^{* *}$ \\
& P2 & & & $<0.013^{* *}$ \\
\hline
\end{tabular}

CR: Conventional radiology; CT: Computed tomography; InR: Interventional radiology P1: significance when comparing with Conventional radiology, P2: significance when comparing with Computed tomography. **: Statistically significant at $\mathbf{P}<\mathbf{0 . 0 1}$ 
However, GSH levels were significantly increased after oral administration of NAC (600 mg) twice daily for two months when compared to the MRWs group and subgroups before administration of this drug $(\mathrm{P}<0.05)$ and insignificantly increased than control ( $P>0.05)$, Table (3) and Figure (1).

In this study, a significant increase in the levels of MDA and AOPPs in MRWs group was found compared to the control $(\mathrm{P}<0.001)$. Taking a closer investigation of the occupational setting subgroups, a significant difference was observed between the InR subgroup and the $\mathrm{CR}$ and $\mathrm{CT}$ subgroups $\quad(4.7 \pm 0.27, \quad 2.6 \pm 0.38, \quad 3.90 \pm 0.40$ $\mathrm{nmol} / \mathrm{ml}, \quad 302.25 \pm 7.50, \quad 62.00 \pm 19.23$, and $147.89 \pm 80.33 \mu \mathrm{mol} / \mathrm{L}, \quad$ respectively, $\mathrm{P}<0.01$ ). Also, The CT subgroup displayed a significant increase in the levels of MDA and AOPPs when compared to $\mathrm{CR}$ subgroup $(\mathrm{P}<0.01)$, Table (3) and Figure (1).

While MDA and AOPPs levels were significantly reduced after oral administration of NAC when compared to MRWs group and subgroups before receiving this drug $(\mathrm{P}<0.001)$ and insignificantly decreased versus control group $(\mathrm{P}>0.05)$. The highest MDA and AOPPs levels were observed in the InR subgroup, but the lowest levels were detected in the CR subgroup, Table (3) and Figure (1).

\section{Discussion}

In the current research, it was the first time, to observe an increase in erythrocyte GSH and decrease in plasma MDA and AOPPS levels in medical radiation workers after oral administration of NAC. Many previous studies reported a decrease in GSH levels in MRWs group and were agreed with our result [20-26]. Interventional radiology workers subgroup showed lower GSH levels than the CR and CT workers subgroups. This decline in GSH levels was resulted from the increase of the reactive oxygen radicals that produced from chronic exposure to IR. [27]

Durovic B et.al. [28] disagreed with our results as they found no change in the levels of reduced glutathione between MRWs group and control group. This disagreement may be due to the difference in examined groups between the two studies and also the alteration in the radiological procedures, machines and the used protocol [28].

NAC treatment was used to overcome the decrease in the antioxidant capacity that was induced by IR chronic exposure since it is one of the frequently used antioxidant drugs, safe and well tolerated supplementary medication without any considerable side effects. It has been used in clinical field for more than four decades. NAC has a powerful influence on diseases and states characterized by the production of free oxygen radicals. It protects mice from gastrointestinal death after abdominal irradiation where administration of NAC restored mice's duodenal structure exposed to $20 \mathrm{~Gy}$ and mitigated the life shortening induced by chronic exposure to low dose rate of radiation in mice [7, 20, 29-31].

Table (3): Comparison between the control and the medical radiation workers before and after administration of NAC

\begin{tabular}{|c|c|c|c|c|c|c|}
\hline \multirow{2}{*}{$\begin{array}{l}\text { Biochemical } \\
\text { Parameters }\end{array}$} & \multirow{2}{*}{ Control } & \multicolumn{2}{|c|}{ radiation exposed workers } & \multicolumn{3}{|c|}{ Probability } \\
\hline & & Before & After & P1 & $\mathbf{P}_{2}$ & $\mathbf{P}_{3}$ \\
\hline \multicolumn{7}{|l|}{ GSH (mmol/L) } \\
\hline Min. - Max. & $0.04-0.98$ & $0.002-0.05$ & $0.05-0.13$ & $\mathrm{U}=8.00^{*}$ & $\mathrm{U}=181.0$ & $\mathrm{Z}=4.372^{*}$ \\
\hline Mean \pm SD. & $0.14 \pm$ & $0.02 \pm 0.02$ & $0.08 \pm 0.02$ & $<0.001 * * *$ & $p=0.115$ & $<0.001 * * *$ \\
\hline Median & & 0.01 & 0.08 & & & \\
\hline \multicolumn{7}{|l|}{ MAD (nmol/ml) } \\
\hline Min. - Max. & $0.73-2.92$ & $2.057-5.01$ & $0.38-2.37$ & $\mathrm{t}=6.923^{*}$ & $t=2.007$ & $\mathrm{t}=10.655^{*}$ \\
\hline Mean \pm SD. & $1.72 \pm 0.63$ & $3.40 \pm 0.93$ & $1.34 \pm 0.50$ & $<0.001 * * *$ & 0.053 & $<0.001 * * *$ \\
\hline Median & 1.69 & 3.32 & 1.46 & & & \\
\hline \multicolumn{7}{|c|}{ AOPPs $(\mu \mathrm{mol} / \mathrm{L})$} \\
\hline Min. - Max. & $10.0-75.00$ & $23.0-306.00$ & $10.0-292.00$ & $\mathrm{U}=104.50 *$ & $\mathrm{U}=219.0$ & $\mathrm{Z}=3.823^{*}$ \\
\hline Mean \pm SD. & $46.95 \pm 18.02$ & 131 & $64.21 \pm 61.05$ & $0.004 * * *$ & 0.825 & $<0.001 * * *$ \\
\hline Median & 50.0 & 75.0 & 43.0 & & & \\
\hline
\end{tabular}

U: Mann Whitney test, t: Paired t-test, Z: Wilcoxon signed ranks test, P1: p value for comparing between control and before groups, P2: p value for comparing between control and after groups, P3: $p$ value for comparing between before and after group. *: Statistically significant at $\mathbf{P}<0.05$, ***: Statistically significant at $\mathbf{P}<\mathbf{0 . 0 0 1}$ 
GSH levels in MRWs supported with oral administration of NAC (600 mg) twice daily for two months were significantly increased by 4.6 times than before administration of NAC. This showed the protective effect of NAC as it stimulates reduced glutathione biosynthesis and acts as -SH donor [17, 23, 29-35]. Kasperczyk S et.al. [25] dedicated that administration of NAC 400 and $800 \mathrm{mg}$ of NAC for 12 weeks could decrease oxidative stress in workers exposed to lead by increasing GSH synthesis and also Kuyumcu et.al. [24] and Holmay MJ. et.al. [26] are agreed with the present results.

The levels of MDA in the MRWs group were significantly higher(100\%) than the control group and as the average annual effective dose increased the MDA levels increased which observed in the different MRWs subgroups (CR, CT and InR). These results are in agreement with many previous studies which stressed that chronic exposure to low doses of IR caused an increase in the oxidative stress molecules as MDA which is the most mutagenic product that resulted from peroxidation of lipids when ROS oxidizes lipids and leading to tissue damage and cell membrane damage. This harmful effect is the molecular base for disruption of signal transduction, gene expression and regulation of cell functions involved in apoptosis, adaptation and genomic instability which are directly associated to carcinogenesis[7, 27, 36].

Oral effervescent of NAC significantly reduced MDA levels in MRWs group by 2.5 times than before giving this drug. This decline represented the role of NAC in detoxification, as it acts directly as a free radicals scavenger by increasing GSH levels and a lot of the previous studies were consistent with our results [16, 17, 28, 29, 33, 37].

Excessive ROS accumulation results in the formation of AOPPs through oxidative stress by the interaction between plasma proteins, mainly albumin, and chlorinated oxidants. AOPPs is a protein oxidative marker [9, 10, 38, 39]. The levels of AOPPs in the MRWs group were significantly higher than the control group (2.8 times). AOPPs levels in the InR subgroup were 2 times and 4.9 times higher than $\mathrm{CT}$ and $\mathrm{CR}$ subgroups, respectively. The alterations in these biochemical markers between MRWs and non- radiation workers have reflected the potential health problems that raised from persistent exposure to low doses of IR in radiology technicians.

The levels of AOPPs were significantly decreased to half its value after using NAC. This reduction in AOPPs levels displayed the radioprotective effect of NAC by repressing ROS generation induced by IR [27]. Also, the results of Lazárová M, et. al. [40] were in agreement with the current results as they reported that serum AOPPs was significantly fallen after oral administration of $600 \mathrm{mg}$ NAC for 20 days.

\section{Conclusion}

Prolonged exposure to low doses of IR caused an increase in the oxidative stress which was reflected in decreasing in erythrocyte GSH and increasing in plasma MDA and AOPPs levels. NAC ameliorated oxidative stress by eliminating ROS through increasing GSH levels and decreasing MDA and AOPPs levels.

Further studies will be needed on larger number of workers and study other biochemical and molecular markers to confirm the role of NAC in protecting medical radiation workers.

Furthermore, increasing the awareness about the dangerous effects of low doses of ionizing radiation among MRWs and regular monitoring by periodic health examination is necessary. 


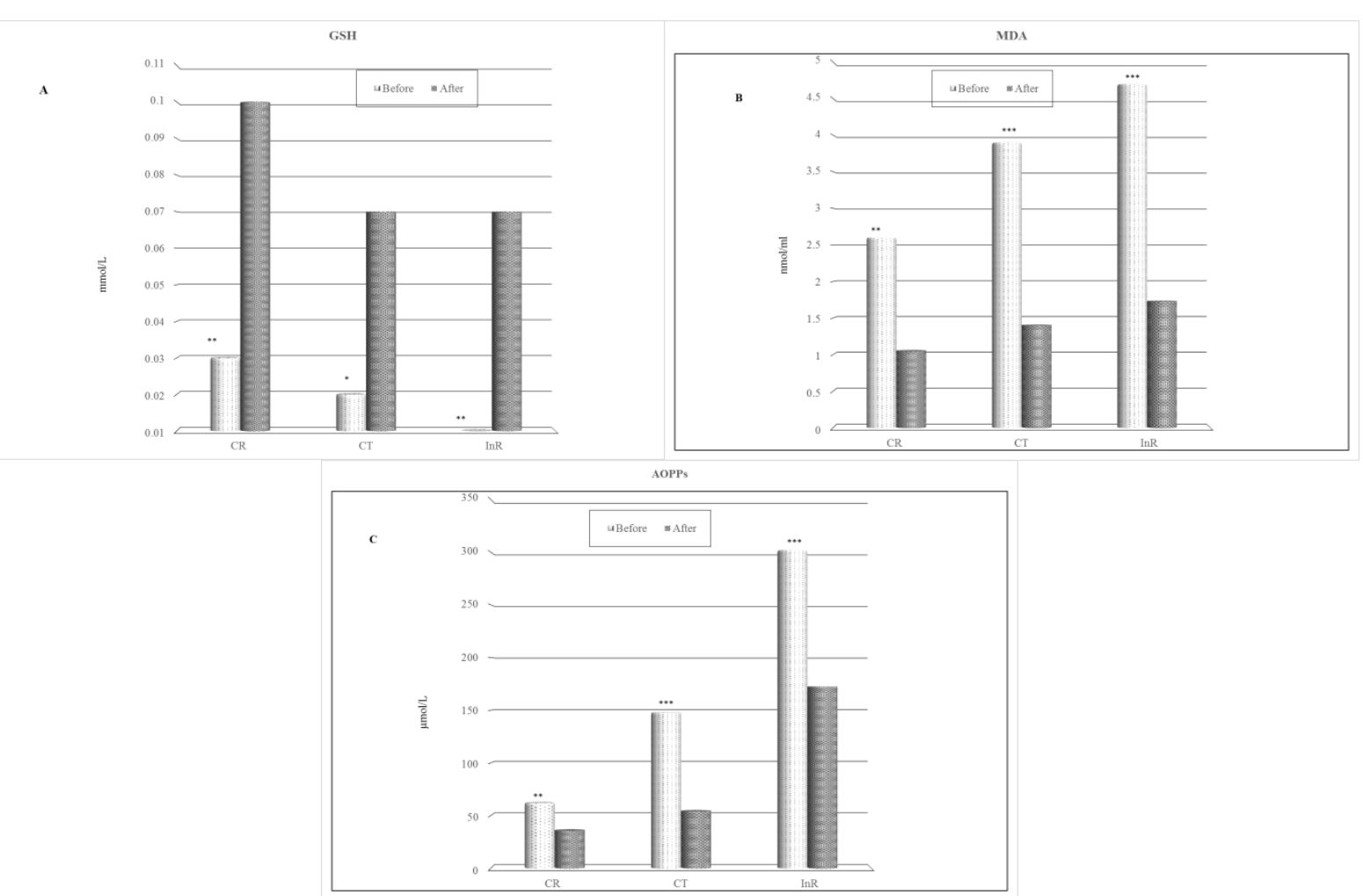

Figure (1): Comparison between medical radiation workers subgroups before and after administration of NAC. (A) Glutathione (mmol/L). (B) Malondialdehide (nmol/ml). (C) Advanced oxidation protein products ( $\mu \mathrm{mol} / \mathrm{L}$ )

*: Statistically significant at $\mathbf{P}<0.05, * *$ : Statistically significant at $\mathbf{P}<0.01, * * *$ : Statistically significant at $\mathbf{P}<$ 0.001

\section{References}

1-Vaiserman A, Koliada A, Zabuga O, et al. (2018). Health Impacts of Low-

Dose Ionizing Radiation: Current Scientific Debates and Regulatory Issues. Dose Response, https://doi.org/10.1177/155932581879633 1.

2-Shahid S and Masood K (2018) Assessing liver proteins and enzymes of medical workers exposed to ionizing radiation (IR). Clin Exp Med, 18:89-99.

3-International Agency for Research on Cancer (IARC). 2000. Monographs on the evaluation of carcinogenic risks to humans, working group on the evaluation of carcinogenic risks to humans of ionizing radiation, $\mathrm{X}$-ray and gamma-radiation and neutrons. IARC.75:1-448.

4-Wang F, Sun Q, Wang J, et al. (2016) Risk of developing cancers due to low-dose radiation exposure among medical X-ray workers in Chinaresults of a prospective study. Int J Clin Exp Pathol, 9:11897-11903.

5-Lee WJ, Choi Y, Ko S3 et al. (2018). Projected lifetime cancer risks from occupational radiation exposure among diagnostic medical radiation workers in South Korea. BMC Cancer https://doi.org/10.1186/s12885-018-5107-X.
6-Siama Z, Zosangzuali M, Vanlalruati A, et al. (2019) Chronic Low Dose Exposure of Hospital Workers to Ionizing Radiation Leads to Increased Micronuclei Frequency and Reduced Antioxidants in Their Peripheral Blood Lymphocytes. Int J of Radiat Biol, 95:697-709.

7-Šalamon Š, Kramar B, Marolt TP, et al. (2019). Medical and Dietary Uses of N-Acetylcysteine. Antioxidants, https://doi.org/10.3390/antiox8050111.

8-Gaschler MM and Stockwell BR. (2017) Lipid peroxidation in cell death. Biochem Biophys Res Comm, 482:419-425.

9-Egea J, Fabregat I, Frapart YM, et al. (2017) European contribution to the study of ROS: A summary of the findings and prospects for the future from the COST action BM1203 (EU-ROS). Redox Biol, 13: 94-162.

10-Gray MJ, Wholey WY and Jakob U (2013) Bacterial Responses to Reactive Chlorine Species. Annu Rev Microbiol, 67: 141-160.

11-World Health Organization. WHO Model List of Essential Medicines: 20th List. March 2017.

12-De Oliveira CP, Stefano J, De Siqueira ER, et al. (2008) Combination of N-acetylcysteine and metformin improves histological steatosis and fibrosis in patients with non-alcoholic steatohepatitis. Hepatol Res, 38:159-165. 
13-Tse $\mathrm{H} \mathrm{N}$ and Tseng CZ. (2014) Update on the pathological processes, molecular biology, and clinical utility of $\mathrm{N}$-acetylcysteine in chronic obstructive pulmonary disease. Int J Chron Obstruct Pulmon Dis, 9: 825-836.

14-Pirabbasi E, Shahar S, Manaf ZA, et al. (2016) Efficacy of Ascorbic Acid (Vitamin C) and/NAcetylcysteine (NAC) Supplementation on Nutritional and Antioxidant Status of Male Chronic Obstructive Pulmonary Disease (COPD) Patients. J. Nutr. Sci. Vitaminol. (Tokyo), 62: 54-61.

15-Stey C, Steurer J, Bachmann S, et al. (2000) The effect of oral $\mathrm{N}$-acetylcysteine in chronic bronchitis: a quantitative systematic review. Eur Respir J, 16: 253-262.

16-Prescott LF, Park J, Ballantyne A, et al. (1977) Treatment of paracetamol (acetaminophen) poisoning with N-acetylcysteine. Lancet, 2: 432-434.

17-Samuni Y, Goldstein S, Dean OM et al. (2013) The chemistry and biological activities of Nacetylcysteine. Biochim Biophys Acta, 1830:41174129.

18-Kotz S, Balakrishnan N, Read CB, et al. (2006) Encyclopedia of statistical sciences. 2nd ed. Hoboken, N.J.: Wiley-Interscience.

19-Kirkpatrick LA, Feeney BC (2013) A simple guide to IBM SPSS statistics for version 20.0. Student ed. Belmont, Calif.: Wadsworth, Cengage Learning.

20-Koc U, Tan S, Ertem AG, et al. (2017) Evaluation of Thiol-Disulphide Homeostasis in Radiation Workers. Int J of Radiat Biol, 93:705-710.

21-Russo GL, Tedesco I, Russo M, et al. (2012) Cellular adaptive response to chronic radiation exposure in interventional cardiologists. Eur Heart J, 33:408-414.

22-Ahmad I M, Abdalla MY, Moore TA, et al. (2019). Healthcare Workers Occupationally Exposed to Ionizing Radiation Exhibit Altered Levels of Inflammatory Cytokines and Redox Parameters. Antioxidants, https://doi.org/10.3390/antiox8010012.

23-Shimura T, Kobayashi J, Komatsu K et al. (2016) Severe mitochondrial damage associated with lowdose radiation sensitivity in ATM- and NBS1deficient cells. Cell Cycle, 15: 1099-1107.

24-Kuyumcu A, Akyol A, Buyuktuncer Z, et al. (2015). Improved oxidative status in major abdominal surgery patients after N-acetyl cystein supplementation. Nut J, https://doi.org/10.1186/14752891-14-4.

25-Kasperczyk S, Dobrakowski M, Kasperczyk A, et al. (2013) The administration of N-acetylcysteine reduces oxidative stress and regulates glutathione metabolism in the blood cells of workers exposed to lead. Clin Toxicol (Phila), 51:480-486.

26-Holmay MJ, Terpstra M, Coles LD, et al. (2013) Nacetylcysteine boosts brain and blood glutathione in Gaucher and Parkinson diseases. Clin Neuropharmacol, 36:103-106.
27-Topcu1 A, Mercantepe F, Rakici S, et al. (2019) An investigation of the effects of $\mathrm{N}$-acetylcysteine on radiotherapy-induced testicular injury in rats. Naunyn Schmiedebergs Arch of Pharmacol, 392:147-157.

28-Durovic B, Spasic-Jokic V, Durovic B (2008) Influence of occupational exposure to low-dose ionizing radiation on the plasma activity of superoxide dismutase and glutathione level. Vojnosanit Pregl, 65:613-618.

29-Reliene R, Pollard JM, Sobol Z, et al. (2009) Nacetyl cysteine protects against ionizing radiationinduced DNA damage but not against cell killing in yeast and mammals. Mutat Res, 665:37-43.

30-Jia D, Koonce NA, Griffin RJ, et al. (2010) Prevention and Mitigation of Acute Death of Mice after Abdominal Irradiation by the Antioxidant NAcetyl-cysteine (NAC). Radiat Res, 173:579-589.

31-Yamauchi K, Tsutsumi Y, Ichinohe K (2019) Effects of $\mathrm{N}$-acetylcysteine on life shortening induced by chronic low dose-rate gamma-ray exposure in mice. Int J Radiat Res, 17: 67-73

32-Wang Q, Hou Y, Yi D, et al. (2013). Protective effects of $\mathrm{N}$-acetylcysteine on acetic acid-induced colitis in a porcine model. BMC Gastroenterol, https://doi.org/10.1186/1471-230X-13-133.

33-Mokhtari V, Afsharian P, Shahhoseini M, et al. (2017) A Review on Various Uses of N-Acetyl Cysteine. Cell J, 19:11-17.

34-Zafarullah M, Li WQ, Sylvester J, et al. (2003) Molecular mechanisms of Nacetylcysteine actions. Cell Mol Life Sci, 60: 6-20.

35-Das KC, Lewis-Molock Y, White CW. (1995) Activation of NF-kappa B and elevation of MnSOD gene expression by thiol reducing agents in lung adenocarcinoma (A549) cells. Am J Physiol, 269:L588-602.

36-Rosi A, Grande S, Luciani AM, et al. (2007) Role of Glutathione in Apoptosis Induced by Radiation as Determined by ${ }^{1} \mathrm{H}$ MR Spectra of Cultured Tumor Cells. Radiat Res, 167:268-282.

37-Rani V, Deep G, Singh RK, et al. (2016) Oxidative stress and metabolic disorders: pathogenesis and therapeutic strategies. Life Sci, 148:183-193.

38-Ahmad IM, Temme JB, Abdalla MB, et al. (2016) Redox Status in Workers Occupationally Exposed to Long Term Low Levels of Ionizing Radiation - A pilot study. Redox Rep, 21: 139-145.

39-Chaoqun YU, Huang D, Wang K, et al. (2017) Advanced oxidation protein products induce apoptosis, and upregulate sclerostin and RANKL expression, in osteocytic MLO-Y4 cells via JNK/p38 MAPK activation. Mol Med Rep, 15: 543-550.

40-Lazárová M, Stejskal D, Lacnák B, et al. (2004) The antioxidant acetylcysteine reduces oxidative stress by decreasing level of AOPPs Biomed Papers , 148: 131-133. 